\title{
Surgical endodontic management after conventional root canal treatment failure: A case report
}

\author{
Nidhi Rani', Rajesh Kumar Gupta ${ }^{2, *}$, Ashish Karode ${ }^{3}$ \\ ${ }^{1}$ Senior Resident, ${ }^{2}$ Senior Lecturer, ${ }^{3}$ Medical Officer, ${ }^{1,3}$ Dept. of Conservative Dentistry and Endodontics, ${ }^{2}$ Dept. of \\ Periodontology, ${ }^{1}$ Postgraduate Institute of Medical Education \& Research, Chandigarh, ${ }^{2}$ Bhojia Dental College \& Hospital, \\ Himachal Pradesh, ${ }^{3}$ Civil Hospital Maharashtra, India
}

*Corresponding Author:

Email: rajeshguptafzk@gmail.com

\begin{abstract}
In the root canal system, infection of the pulp tissue caused by caries or other pathways is the primary cause of apical periodontitis. The ultimate goal of the endodontic treatment is to create adequate conditions for periradicular tissue healing. Nonsurgical endodontic treatment is a highly predictable treatment option in most cases, but surgery may be indicated for teeth with persistent periradicular pathosis unresponsive to nonsurgical approaches. The aim of this article is to highlight the possibility of the successful outcome of surgical endodontic treatment following failed non surgical treatment of right maxillary central incisor. With proper case selection and operator skill, periradicular surgery can be considered predictable, cost effective alternative to tooth extraction and tooth replacement.
\end{abstract}

Keywords: Apicoectomy, Retreatment, Biodentine, Ultrasonic retrotips.

\section{Introduction}

Conventional endodontic treatment aims to eliminate bacteria from root canal system and establish effective barriers against root recontamination. ${ }^{1}$ To achieve success, cleaning, shaping and filling of the entire root canal system are considered essential steps in endodontic therapy. Failure factors in conventional root canal treatment are frequently related to the presence of residual bacteria (persistent infection) or reinfection in a previously disinfected canal (secondary infection). ${ }^{2}$

Endodontic surgery comprehends a set of procedures recommended in periapical diseases treatment, when conventional endodontic therapy does not obtain favourable outcomes. Indications for periapical surgery are: root canal obliteration impeding endodontic instrumentation access to apical region; endodontic material apical extrusion impeding radiolucent lesions repair and/or causing clinical symptoms; unsuccessful endodontic treatment and retreatment impossibility due to prosthesis; root perforation impeding root canal hermetic sealing. The goal of periradicular surgery is removal of lesion and sealing of apical third root dentine, which allows soft and hard tissue regeneration. ${ }^{3,4}$

Historically, this operation was reported 4500 years ago in the form of simple cortical trephination. Around the $11^{\text {th }}$ Century AD, Abulcasis, an Arabian physician described the first case of apicoectomy in his medical encyclopaedia, Altasrif. ${ }^{5}$ A root end resection procedure to manage a tooth with necrotic pulp and alveolar abscess was documented in $1871,{ }^{6}$ and root end resection with retrograde cavity preparation and filling with amalgam was documented in 1890 's. ${ }^{7}$ A study of 797 apicectomy by Nordenram and Svardstrom ${ }^{8}$ reported a success rate of $64 \%$ with the best results found when root filling and apicectomy were carried out at the same visit when the periapical lesion was less than $5 \mathrm{~mm}$ in diameter. A retrospective study by Oginni and Olusile ${ }^{9}$ showed the success rate of apicoectomy of anterior teeth to be $71.9 \%$.

The aim of the present case report was to present the surgical endodontic management following failed non surgical treatment of right maxillary central incisor.

\section{Case Report}

A 24 year-old female patient reported to the Department of Conservative Dentistry and Endodontics at Punjab Government Dental College and Hospital, Amritsar, complaining about pain in the upper front teeth since three weeks. Maxillary right central and lateral incisors were tender on clinical examination. No introral swelling and sinus were observed. Radiographic examination revealed poor root canal filling with respect to 11 with extrusion of the gutta percha into periapical tissues and periapical radiolucency about $2 \mathrm{~cm}$ in diameter involving the root apices of 11 and 12 (Fig. 1a).

Tooth 12 did not respond to electric pulp testing. Endodontic surgery was recommended to the patient. Endodontic treatment of 12 and retreatment of 11 was completed (Fig. 1b). After seven days, periradicular area of 11 and 12 was exposed. Pathological tissue was curetted out and root ends were resected about $3 \mathrm{~mm}$ with a surgical straight carbide bur at shallow angle (Fig. c, d). Haemostasis was achieved by means of gauze packing. Mini-Class I cavities in the apical regions of the resected root ends were prepared by using ultrasonic stainless steel angled retrotips. The operative field was then isolated and the cavities were filled with Biodentin (Fig. 1e). The bony cavity was thoroughly irrigated. The flap was repositioned and 
sutured. Postoperative medications and instructions were given to the patient.

No tenderness, swelling and sinus were detected at the follow up visits. One year follow up radiograph showed good periradicular healing (Fig. 1f).

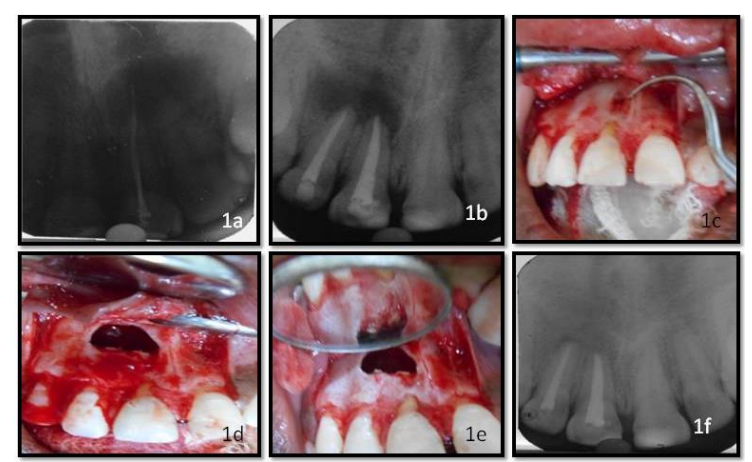

Fig.1a: Pre-operative radiograph, (1b: obtuartion done, (1c: Depicting the defect, (1d: Periapical lesion curetted out and root ends resected, (1e: Mini class 1 cavities prepared and filled with Biodentin, (1f: 1 year follow up radiograph showing good periradicular healing

\section{Discussion}

Endodontic surgery is a procedure which consists of the removal of pathological periapical tissue, thus, reaching the goal of creating the best conditions to the tissue health, regeneration and creation of new tooth structural support.

The success of endodontic surgery ranges from 53 to $98 \%$ when performed the first time, ${ }^{10-12}$ while that for retreatment cases with periapical lesion is lower. ${ }^{13,14}$ The histological status of a periapical lesion shown as a radiolucent lesion on a radiograph, is unknown to the clinicians at the time of treatment from a purely pathological point of view. Approximately $10 \%$ of all periapical lesions require surgery in addition to endodontic treatment. In addition, failed re-treatment cases because of apical transportation or procedural errors are best treated by surgical endodontics, especially if they have post restorations. Further, the complexity of the canal anatomy does not allow $100 \%$ success in nonsurgical endodontic therapy.

The major cause of periapical lesion is a leaky apical seal with egress of microorganisms and their toxins. Removal of the diseased periapical tissue by periradicular curettage eliminates only the effect of the leakage, not the cause. Thus, the elimination of periradicular lesion alone will likely result in the recurrence of the lesion if the root end is not resected. Root-end amputation of about $3 \mathrm{~mm}$ removes all of the lateral canals and apical ramifications, therefore, posing less risk of reinfection and eventual failure.

Biodentine as root end filling material offer several advantages like better consistency, safety, better handling and faster setting time which creates no need for a two step obturation. ${ }^{15}$ Biodentine induces mineralization after its application. Mineralization occurs in the form of osteodentine by expressing markers of odontoblasts and increases TGF- $\beta_{1}$ secretion from pulpal cells enabling early mineralization.

In the present case, periradicular surgery was planned after non surgical endodontic intervention of 11 and 12. Pathological periapical tissue was curetted out and root ends of 11 and 12 were resected about $3 \mathrm{~mm}$ at shallow bevel angle related to tooth long axis. With the traditional rotary bur, the steep bevel angle of 45 to 60 degrees was recommended. The purpose of this steep bevel was simply for access and visibility but it will expose the large number of dentinal tubules. Furthermore, bevelling frequently misses the lingually positioned apex, causes elongation of the canal and reduction of the root diameter, thereby weakening it. ${ }^{16-}$ 18

Root end cavities were prepared using ultrasonic retro tips. Richman first introduced the use of ultrasonics in endodontics in 1957, using a modified ultrasonic periodontal chisel scaler for root canal debridement and apicoectomy. ${ }^{19}$ Several authors later reported that retro tips had superior operator control, decreased risk of perforation by increased ability to stay centred in the canal as compared to the microhandpiece. ${ }^{20}$ After retro cavity preparation, Biodentin was used as root end filling.

In the present case, patient was asymptomatic and 1 year follow up radiograph revealed complete healing of periradicular tissue.

\section{Conclusion}

When conventional endodontic treatment proves insufficient the clinician must consider treatment alternatives. Not all failures are amenable to nonsurgical retreatment. Clinicians need to weigh risk versus benefit and recognize that, at times, surgery or extraction might be in the patient's best interest.

\section{References}

1. Kim S, Kratchman S. Modern endodontic surgery concepts and practice: a review. J Endod 2006;32:601-23.

2. Siqueira Jr JF. Reaction of periradicular tissues to root canal treatment: benefits and drawbacks. Endod Topics 2005;10:123-47.

3. Matherne RP, Angelopoulos C, Kulild JC, Tira D. Use of cone-beam computed tomography to identify root canal systems in vitro. J Endod 2008;34:87-9.

4. Von Arx T, Gerber C, Hardt N. Periradicular surgery of molars: a prospective clinical study with a one-year follow-up. Int Endod J 2001;34:520-5.

5. Weinburger BW. An Introduction to theHistory of Dentistry. Vol 1. CV Mosby Co, St Louis. 1948; p:71.

6. Smith CS. Alveolar abscess. Am J Dent Sci. 1871;5:289300 .

7. Lucas CD. Root resection and apical canal filling after resection. Dent Summary. 1916;36:201-207.

8. Nordenram A, Svardstrom G. Results of apicectomy. Svensk Tandlakara Tidskr. 1970;63:593-604. 
9. Oginni AO, Olsuile AO. Follow-up study of apicectomised anterior teeth. S Afr Dent J. 2002; 57:136140.

10. Saunders WP, Saunders EM. Coronal leakage as a cause of failure in root-canal therapy (a review). Endod and Dent Traumatology 1994;10:105-8.

11. Kerekes K. Tronstad L. Long-term results of endodontic treatment performed with a standardized technique. $\mathrm{J}$ Endod 1979;5:83-90.

12. Jokinen MA, Kotilainen R, Poikkeus P, et al. Clinical and radiographic study of pulpectomy and root canal therapy. Scand J Dent Res 1978;86:366-73.

13. Bergenholtz G, Lekholm U, Milthon R, Heden G, Odesjo B, Engstrom B. Retreatment of endodontic fillings. Scand J Dent Res 1979;87:217-24.

14. Gorni FG, Gagliani MM. The outcome of endodontic retreatment: a 2-yr follow-up. J Endod 2004;30:1-4.

15. Meshack RA, Velkrishna K, Chakravarthy PVK, Nerali J. Overview of Root End Filling Materials. Int J Clin Dent Science 2012;3:1-7.

16. Kim S, Pecora G, Rubinstein R. Comparison of traditional and microsurgery in endodontics. In: Kim S, Pecora G, Rubinstein R, eds. Color atlas of microsurgery in endodontics. Philadelphia: W.B. Saunders, 2001:5-11.

17. Carr GB. Surgical endodontics. In: Cohen S, Burns R, eds. Pathways of the pulp, $6^{\text {th }}$ ed. St Louis: Mosby, 1994:531.

18. Kim S. Endodontic microsurgery. In: Cohen S, Burns R, eds. Pathways of the pulp, 8th ed. St Louis: Mosby, 2002:683-721.

19. Richman MJ. The use of ultrasonics in root canal therapy and resection. J Dent Med 1957;12:12-8.

20. Engel TK, Steiman HR. Preliminary investigation of ultrasonic root-end preparation. J Endod 1995;21:443-8. 